TITLE:

\title{
Bound of earthquake input energy to building structure considering shallow and deep ground uncertainties
}

\author{
$\operatorname{AUTHOR}(\mathrm{S})$ : \\ Taniguchi, M.; Takewaki, I.
}

\section{CITATION:}

Taniguchi, M....[et al]. Bound of earthquake input energy to building structure considering shallow and deep ground uncertainties. Soil Dynamics and Earthquake Engineering 2015, 77: $267-273$

ISSUE DATE:

2015-10

URL:

http://hdl.handle.net/2433/201373

\section{RIGHT:}

(c) 2015. This manuscript version is made available under the CC-BY-NC-ND 4.0 license

http://creativecommons.org/licenses/by-nc-nd/4.0/; The full-text file will be made open to the public on 31 October 2017 in accordance with publisher's 'Terms and Conditions for Self-Archiving'., この論文は出版社版でありません。引 用の際には出版社版をご確認ご利用ください。; This is not the published version. Please cite only the published version. 


\title{
Bound of earthquake input energy to building structure considering shallow and deep ground uncertainties
}

\author{
M. Taniguchi and I. Takewaki* \\ Department of Architecture and Architectural Engineering, \\ Graduate School of Engineering, Kyoto University, \\ Kyotodaigaku-Katsura, Nishikyo, Kyoto 615-8540, Japan
}

\begin{abstract}
The bound of earthquake input energy to building structures is clarified by considering shallow and deep ground uncertainties and soil-structure interaction. The ground motion amplification in the shallow and deep ground is described by a one-dimensional wave propagation theory. The constant input energy property to a swaying-rocking model with respect to the free-field ground surface input regardless of the soil property is used effectively to derive a bound. An extension of the previous theory for the engineering bedrock surface motion to a general earthquake ground motion model at the earthquake bedrock is made by taking full advantage of the above-mentioned input energy constant property. It is shown through numerical examples that a tight bound of earthquake input energy can be derived for the shallow and deep ground uncertainties.
\end{abstract}

Keywords: Earthquake input energy, Energy transfer function, Swaying-rocking model, Soil-structure interaction, Ground amplification, Shallow and deep ground, Uncertain ground property, Upper bound of input energy

*Corresponding author: E-mail, takewaki@archi.kyoto-u.ac.jp 


\section{Introduction}

On March 11, 2011, the great Tohoku (Japan) earthquake attacked mainly the east part of Japan. Several giant tsunamis arrived the wide area of Tohoku district. That earthquake also shaked many tall buildings severely in Tokyo 200-500km far from the fault region. However it should be reminded that a super high-rise building in the Osaka bay area was shaken more intensively regardless of the fact that Osaka is approximately $800 \mathrm{~km}$ far from the fault region. It has been reported [1, 2] that the deep ground property of the building influenced such phenomenon. This fact clearly indicates that the deep ground property and its uncertainty should be investigated and included in the design of super high-rise buildings.

In the early history of seismic resistant design of building structures, the earthquake input energy was introduced as a stable and important measure together with deformation and acceleration [3]. It was known widely that, while deformation and acceleration are sensitive to the nature of earthquake ground motions, the input energy exhibits a stable characteristic and can take into account the effect of vibration duration. In addition, it has been understood well [4-6] that the input energy is suitable for soil-structure interaction problems because this problem can be expressed in a rational way by considering the exchange of energy between structures and soil.

There exist versatile researches so far on the topics of earthquake input energy (for example, [3, 7-17]). However the earthquake input energy to soil-structure systems has not been thoroughly considered in literature except a few $[6,18,19]$. This may result from the fact that the behavior of a soil-structure system is quite difficult to describe in a simple way and its frequency-dependent characteristic causes a difficulty in incorporating its property in the time-history analysis for computation of input energy. In contrast to most of the previous works, the earthquake input energy is formulated here in the frequency domain $[6,20-24]$ to facilitate the derivation of bound of earthquake input energy which is useful for the design of building structures under uncertain soil conditions.

In order to clarify the energy dissipation mechanism in the soil-structure interaction system, three kinds of input energy have been defined in [19], one to the overall soil-structure interaction system, one to the superstructure only and the other to the foundation-soil system. 
The difference between these three energies indicates the energy dissipated in the soil or that radiating into the ground. It has been demonstrated in [19] that the input energy expressions for the above-mentioned three systems or substructures can be of a compact form via the frequency integration of the product between the input component (Fourier amplitude spectrum) and the substructure model component (so-called energy transfer function). With the help of this compact form, it has been made clear that, when the ground surface motion is white (constant Fourier spectrum), the input energy to the swaying-rocking model is constant regardless of the soil property (input energy constant property). The upper bound of earthquake input energy to the swaying-rocking model has then been derived for the model including the surface ground amplification by taking full advantage of the above-mentioned input energy constant property and introducing the envelope function for the transfer function of the surface ground amplification.

In this paper, the theory developed in [19] (white ground motion at the engineering bedrock) is extended to a general earthquake ground motion model at the earthquake bedrock [25] by taking into account the overall ground motion amplification including the effect of shallow and deep ground with uncertainties. It is shown that the proposed upper bound of input energy is tight owing to the constant input energy property introduced in [19] for white free-field ground surface motion. It is expected that the consideration of uncertainties in shallow and deep ground properties in the evaluation of earthquake input energy to building structures enhances the reliability of the seismic safety of the building structures under uncertain environments.

\section{Earthquake input energy to SR model in time domain subjected to free-field ground motion}

Consider a one-story shear building model (mass $m$, stiffness $k$, damping coefficient $c)$, as shown in Fig.1, supported by swaying and rocking springs $k_{H}, k_{R}$ and dashpots $c_{H}, c_{R}$ and subjected to a horizontal acceleration $\ddot{u}_{g}(t)$ at the free-field ground surface. This model is a simplest model for representing the soil-structure interaction and called the SR (SwayingRocking) model. Let $m_{0}, I_{R 0}, L$ denote the foundation mass, its mass moment of inertia and 
the height of the structural mass from the base. The moment of inertia of structural mass is $I_{R} \cdot$

Let $u_{S}, \theta_{R}$ denote the foundation horizontal displacement and its angle of rotation relative to the free-field. The horizontal displacement of the super-mass relative to the foundation without rocking component is denoted by $u$. The equations of motion of the model in the time domain are expressed as

$$
\mathbf{M u ̈}+\mathbf{C u}+\mathbf{K u}=-\mathbf{M r} \ddot{u}_{g}
$$

where

$$
\begin{aligned}
& \mathbf{M}=\left[\begin{array}{ccc}
m & m & L m \\
m & m_{0}+m & L m \\
L m & L m & L^{2} m+I_{R}+I_{R 0}
\end{array}\right], \mathbf{K}=\operatorname{diag}\left(\begin{array}{lll}
k & k_{H} & k_{R}
\end{array}\right), \mathbf{C}=\operatorname{diag}\left(\begin{array}{ccc}
c & c_{H} & c_{R}
\end{array}\right), \\
& \mathbf{u}=\left(\begin{array}{lll}
u & u_{S} & \theta_{R}
\end{array}\right)^{T}, \mathbf{r}=\left(\begin{array}{lll}
0 & 1 & 0
\end{array}\right)^{T}
\end{aligned}
$$

C represents the structural damping and soil damping. Let us introduce the absolute horizontal displacement $y$ of the super-mass as

$$
y=u+u_{S}+L \theta_{R}
$$

As shown in [19], the earthquake input energy $E_{I}^{A}$ to the SR model is expressed as

$$
E_{I}^{A}=-\int_{0}^{\infty} \dot{\mathbf{u}}^{T} \mathbf{M r} \ddot{u}_{g} d t
$$

\section{Earthquake input energy to SR model in frequency domain}

The earthquake input energy to a linear elastic structure can also be expressed in the frequency domain $[12,18,21-24]$. The derivation for the model shown in Fig.1 can be found in [19]. Therefore only the final result is shown in the following.

Let $U, U_{S}, \Theta_{R}, Y, U_{g}$ denote the Fourier transforms of $u, u_{S}, \theta_{R}, y, u_{g}$ and $H, H_{S}, H_{R}, H_{Y}$ denote the transfer functions of $u, u_{S}, \theta_{R}, y$ to $\ddot{u}_{g}$ to $\ddot{U}_{g}$ as follows.

$$
U / \ddot{U}_{g}=H(\omega), U_{S} / \ddot{U}_{g}=H_{S}(\omega), \Theta_{R} / \ddot{U}_{g}=H_{R}(\omega), Y / \ddot{U}_{g}=H_{Y}(\omega)
$$


The earthquake input energy to the SR model in the frequency domain can be obtained as

$$
E_{I}^{A}=\int_{0}^{\infty} F_{A}(\omega)\left|\ddot{U}_{g}\right|^{2} d \omega
$$

where $F_{A}(\omega)$ is called the energy transfer function of the SR model expressed by

$$
F_{A}(\omega)=\frac{1}{\pi} \operatorname{Re}\left[\frac{1}{\mathrm{i} \omega}\left\{m_{0}\left(\omega^{2} H_{S}-1\right)+m\left(\omega^{2} H_{Y}-1\right)\right\}\right]
$$

$\operatorname{Re}[$ ] denotes the real part.

\section{Property of earthquake input energy to SR model subjected to white-noise-like free-}

\section{field input}

An example of the energy transfer function $F_{A}(\omega)$ was shown in [19]. That function exhibits a peak at the fundamental natural frequency of the SR model. Consider the earthquake input energy to the overall SR model subjected to a white-noise-like free-field input with $\left|\ddot{U}_{g}(\omega)\right|=1$. This quantity is called the 'scaled earthquake input energy' for the free-field input and can be evaluated by

$$
J_{S R}^{F}=\int_{0}^{\infty} F_{A}(\omega) d \omega=\frac{1}{2} \sum m_{i}
$$

The summation is extended to the superstructure masses and the foundation mass. Eq.(8) can be proved by taking into account that a white-noise-like free-field input with $\left|\ddot{U}_{g}(\omega)\right|=1$ is equivalent to the impulsive loading with the initial velocity of 1 in time domain $[19,24]$.

\section{Earthquake input energy to SR model subjected to engineering bedrock input}

Consider a ground model consisting of a uniform surface ground (for example GL- 0m - GL-20m) and a uniform engineering bedrock beneath it. Only vertical wave propagation is considered.

Let $\rho_{1}, V_{S 1}, G_{1}, \beta_{1}$ and $h_{1}$ denote the mass density, the shear wave velocity, the shear modulus, the damping ratio and the depth of the surface ground. The mass density and shear wave velocity of the engineering bedrock are denoted by $\rho_{2}$ and $V_{S 2}$.

Using the one-dimensional wave propagation theory [19] and the acceleration transfer 
function $H_{G}(\omega)$, the free-field surface ground acceleration $\ddot{U}_{g}(\omega)$ in the frequency domain may be related to the outcropping engineering bedrock surface ground acceleration $\ddot{U}_{g 0}(\omega)$ through

$$
\ddot{U}_{g}(\omega)=H_{G}(\omega) \ddot{U}_{g 0}(\omega)
$$

Substitution of Eq.(9) into Eq.(6) leads to

$$
E_{I}^{A}=\int_{0}^{\infty} F_{A}(\omega)\left|H_{G}(\omega)\right|^{2}\left|\ddot{U}_{g 0}(\omega)\right|^{2} d \omega
$$

Let us assume that the squared Fourier amplitude spectrum $\left|\ddot{U}_{g 0}(\omega)\right|^{2}$ at the engineering bedrock surface can be bounded by the following function.

$$
\begin{aligned}
& \left(\left|\ddot{U}_{g 0}(\omega)\right|^{2}\right)^{U}=R_{C}+R_{V}(\omega) \\
& R_{V}(\omega)= \begin{cases}R_{V}(\omega) & \left(0 \leq \omega \leq \omega_{I}\right) \\
0 & \left(\omega_{I} \leq \omega\right)\end{cases}
\end{aligned}
$$

Fig.2 shows an example of the bounding of $\left|\ddot{U}_{g 0}(\omega)\right|^{2}$. The direct upper bound of the earthquake input energy to the SR model subjected to an engineering bedrock surface input can be expressed by substituting Eq.(11) into Eq.(10).

$$
\tilde{E}_{I}^{A}=\int_{0}^{\infty} F_{A}(\omega)\left|H_{G}(\omega)\right|^{2}\left(\left|\ddot{U}_{g 0}(\omega)\right|^{2}\right)^{U} d \omega
$$

By introducing another narrow envelope for $\left|H_{G}(\omega)\right|^{2}$ as shown in Fig.3 and using the property expressed by Eq.(8), a tight upper bound $\tilde{\tilde{E}}_{I}^{A}\left(\geq \tilde{E}_{I}^{A}\right)$ of the earthquake input energy to the SR model subjected to an engineering bedrock surface input can be derived. It should be noted that infinite integration in Eq.(12) can be avoided by introducing the property expressed by Eq.(8) (see [19] for detailed derivation).

Fig.4 illustrates the squared Fourier spectra of three artificial ground motions at engineering bedrock surface and their upper bound model. The corresponding proposed upper bound $\tilde{\tilde{E}}_{I}^{A}$ of the earthquake input energy to the SR model and realized earthquake input energy for these three earthquake ground motions are shown in Fig.5. 


\section{Extension to general ground motion input at earthquake bedrock surface}

Consider a ground model consisting of a uniform surface ground (for example GL- 0m - GL-20m), a uniform engineering bedrock (for example GL-20m - GL-120m) and a deep ground (for example GL-120m - GL-1600m) as shown in Fig.6. Only vertical wave propagation is considered because the main purpose of this paper is to provide a new method for evaluating the upper bound of input energy to the SR model considering uncertainties of shallow and deep ground properties.

Consider next a general ground motion input at the earthquake bedrock surface (outcropping). Its Fourier amplitude $A(\omega)$ is shown in Fig.7. Assume that the upper bound of the squared Fourier amplitude $A(\omega)^{2}$ is given by the following form.

$$
\begin{aligned}
& \left(A(\omega)^{2}\right)^{U}=\bar{R}_{C}+\bar{R}_{V}(\omega) \\
& \bar{R}_{V}(\omega)= \begin{cases}\bar{R}_{V}(\omega) & \left(0 \leq \omega \leq \omega_{I}\right) \\
0 & \left(\omega_{I} \leq \omega\right)\end{cases}
\end{aligned}
$$

This model implies that most earthquake ground motions at the earthquake bedrock surface have a predominant frequency in rather lower frequency range and the components at higher frequencies are bounded by a constant value. The characteristics of this model are well accepted in the field of seismology [25].

Let introduce the acceleration transfer function $H_{G E}(\omega)$ in the deep ground, i.e. $\left|\ddot{U}_{g 0}(\omega)\right|=\left|H_{G E}(\omega)\right| A(\omega) . \quad H_{G E}(\omega)$ can be obtained by using the one-dimensional wave propagation theory as in Section 5. The first upper bound of the earthquake input energy to the SR model under the earthquake bedrock horizontal ground acceleration $a(t)$ may be expressed as

$$
\hat{E}_{I}^{A}=\int_{0}^{\infty} F_{A}(\omega)\left|H_{G}(\omega)\right|^{2}\left|H_{G E}(\omega)\right|^{2}\left(A(\omega)^{2}\right)^{U} d \omega
$$

This bound can be proved by $A(\omega)^{2} \leq\left(A(\omega)^{2}\right)^{U}$ and the property of $F_{A}(\omega)$ as a positive function. As shown above, the following relation holds on the property of $F_{A}(\omega)$.

$$
J_{S R}^{F}=\int_{0}^{\infty} F_{A}(\omega) d \omega=\frac{1}{2} \sum m_{i}
$$


By taking advantage of Eq.(15), the second upper bound of the earthquake input energy to the SR model under the earthquake bedrock horizontal ground acceleration $a(t)$ may be derived as follows.

$$
\begin{aligned}
\hat{E}_{I}^{A}= & \int_{0}^{\infty} F_{A}(\omega)\left\{U_{b}-\left(U_{b}-\left|H_{G}(\omega)\right|^{2}\left|H_{G E}(\omega)\right|^{2}\right)\right\}\left(\bar{R}_{C}+\bar{R}_{V}(\omega)\right) d \omega \\
= & \int_{0}^{\infty} F_{A}(\omega)\left\{U_{b} \bar{R}_{C}+U_{b} \bar{R}_{V}(\omega)-\left(U_{b}-\left|H_{G}(\omega)\right|^{2}\left|H_{G E}(\omega)\right|^{2}\right) \bar{R}_{C}-\left(U_{b}-\left|H_{G}(\omega)\right|^{2}\left|H_{G E}(\omega)\right|^{2}\right) \bar{R}_{V}(\omega)\right\} d \omega \\
& \leq \frac{1}{2} U_{b} \bar{R}_{C} \sum_{i} m_{i}+U_{b} \int_{0}^{\omega_{I}} F_{A}(\omega) \bar{R}_{V}(\omega) d \omega \\
& -\frac{\bar{R}_{C} \int_{0}^{\omega_{V}} F_{A}(\omega)\left(U_{b}-\left|H_{G}(\omega)\right|^{2}\left|H_{G E}(\omega)\right|^{2}\right) d \omega-\int_{0}^{\omega_{I}} F_{A}(\omega)\left(U_{b}-\left|H_{G}(\omega)\right|^{2}\left|H_{G E}(\omega)\right|^{2}\right) \bar{R}_{V}(\omega) d \omega}{}=\hat{\hat{E}}_{I}^{A}
\end{aligned}
$$

The validity of this second upper bound can be proven by the property of $F_{A}(\omega)$ as a positive function, as explained above, and the round-up of the squared surface soil transfer function $\left|H_{G}(\omega)\right|^{2}\left|H_{G E}(\omega)\right|^{2}$ to $U_{b}$ in $\omega_{U} \leq \omega$ (i.e. $\left(U_{b}-\left|H_{G}(\omega)\right|^{2}\left|H_{G E}(\omega)\right|^{2}\right) \rightarrow 0$ in $\omega_{U} \leq \omega$ ) (see Fig.8). Eq.(16) shows that the upper bound of input energy can be computed without infinite integration.

\section{Numerical examples}

Consider a rather stiff soil type 1 . The shear wave velocity $V_{S}$ of the surface ground is set as $200(\mathrm{~m} / \mathrm{s})$. The thickness of the surface ground is $20(\mathrm{~m})$. These shear wave velocity corresponds to the natural period of $0.4(\mathrm{~s})$. The mass density of the surface ground is $\rho_{S}=1.7 \times 10^{3}\left(\mathrm{~kg} / \mathrm{m}^{3}\right)$ and that of the engineering bedrock is assumed to be $\rho_{E}=2.1 \times 10^{3}$ $\left(\mathrm{kg} / \mathrm{m}^{3}\right)$. The shear modulus of the surface ground is given by $G=\rho_{S} V_{S}^{2}, V_{S}=200(\mathrm{~m} / \mathrm{s})$. Poisson's ratio of the surface ground is $v=0.35$. The radius of the foundation is $r=4(\mathrm{~m})$. The shear wave velocity of the engineering bedrock is $400(\mathrm{~m} / \mathrm{s})$. The shallow and deep ground properties are shown in Fig.6 and Table 1.

The swaying and rocking stiffnesses and damping coefficients are computed by the following simple formulae [28]. 


$$
\begin{aligned}
& k_{H}=(6.77 /(1.97-v)) G r, k_{R}=(2.52 /(1.00-v)) G r^{3} \\
& c_{H}=(6.21 /(2.54-v)) \rho V_{S} r^{2}, c_{R}=(0.136 /(1.13-v)) \rho V_{S} r^{4}
\end{aligned}
$$

Although a set of simple frequency-independent coefficients is used here, more complicated frequency-dependent coefficients can be employed without difficulty owing to the frequency formulation in this paper.

The superstructure is modeled as a five-story shear building model and each floor mass is $51,200(\mathrm{~kg})$. The equal story height is $3.5(\mathrm{~m})$. The superstructure is transformed into a single-degree-of-freedom model by assuming a triangular lowest mode for a fixed-base model. The structural and foundation parameters are shown in Table 2.

Only examples are shown here for the case where the input ground motion at the earthquake bedrock is certain and the Fourier amplitude spectrum of the input acceleration is given by the theory due to Boore [25]. The parameters for the ground motion input at the earthquake bedrock surface are shown in Table 3.

Assume that the properties of the shallow and deep grounds are uncertain. The mass densities, shear wave velocities and damping ratios are changed in the interval of 0.8-1.2 around the nominal values.

Fig.9 shows the Fourier spectrum at the earthquake bedrock surface derived by the theory due to Boore [25]. The transfer function of the shallow ground and that of the deep ground of the nominal model are presented in Figs.10 and 11, respectively. The transfer function of the overall ground of the nominal model is illustrated in Figs.12.

Three variation cases in shallow, deep and overall grounds are considered as shown in Fig.13. Fig.14 shows the envelope, nominal and realization (27 combinations) of the transfer function of the shallow ground in case of uncertain shallow ground properties (see Fig.13(a)). In the variations, 3 mass densities $(0.8,1.0,1.2$ multiples of the nominal value), 3 shear wave velocities (0.8, 1.0, 1.2 multiples of the nominal value) and 3 damping ratios $(0.8,1.0,1.2$ multiples of the nominal value) have been considered. Although an example of envelope of the transfer function of the shallow ground is shown in Fig.14, a more complete estimation of envelope can be derived by introducing the assumption 'inclusion monotonic' in the field of interval analysis [29]. 
On the other hand, Fig.15 illustrates the envelope, nominal and realization (27 combinations) of the transfer function of the deep ground in case of uncertain shallow ground properties (see Fig.13(b)). As in Fig.14, 3 mass densities (0.8, 1.0, 1.2 multiples of the nominal value), 3 shear wave velocities (0.8, 1.0, 1.2 multiples of the nominal value) and 3 damping ratios $(0.8,1.0,1.2$ multiples of the nominal value) have been considered.

Finally Fig.16 indicates the proposed upper bound (Eq.(16)) of earthquake input energy to the SR model on uncertain shallow and deep grounds subjected to a certain input at the earthquake bedrock. The uncertain parameter variation in this case is shown in Fig.13(c) and 27 parameter combinations have been treated. As in Figs.14 and 15, 3 mass densities (0.8, 1.0, 1.2 multiples of the nominal value), 3 shear wave velocities $(0.8,1.0,1.2$ multiples of the nominal value) and 3 damping ratios (0.8, 1.0, 1.2 multiples of the nominal value) have been considered. Fig.16 clearly demonstrates that the proposed upper bound is reliable and tight, i.e. can bound the realizations in an accurate manner. It can also be observed that the input energy exhibits a rather remarkable value even around the natural period of 6(s) which corresponds to the fundamental natural period of the deep ground. This property has been reported [1] in a tall building in Osaka bay area during the March 11, 2011 Tohoku earthquake and this clear demonstrates the importance of taking into account the deep ground structure and its uncertainty in the structural design of super high-rise buildings.

The present paper has the limitations that the method is based on a linear elastic model and vertically incident waves in parallel layers of soil. As for the frequency dependency, because the present formulation is based on the frequency-domain formulation, it is possible to deal with the frequency-dependent impedance of foundations. It was made clear (Trifunac et al. [30]) that the site frequencies are not repeated even for small earthquakes, due to differences in the incident angles and due to soil nonlinearity for stronger shaking. This phenomenon should be reflected in the formulation in the future.

\section{Conclusions}

The conclusions may be summarized as follows:

(1) It has been shown that the earthquake input energy to a swaying-rocking model in a 
frequency domain can be described by the frequency integration of the energy transfer function with respect to the free-field ground surface, the squared transfer function of the shallow ground, the squared transfer function of the deep ground and the squared Fourier amplitude of the input acceleration at the earthquake bedrock. The ground motion amplification in the shallow and deep ground has been described by a one-dimensional wave propagation theory.

(2) An upper bound of earthquake input energy to the swaying-rocking model is derived for the model including the uncertain shallow and deep ground amplification by taking full advantage of the property derived in [19] (constant input energy to the SR model under the white-like ground surface motion) and an envelope of the shallow and deep ground amplification (squared transfer function). Numerical examples demonstrated that the proposed upper bound is a tight upper bound.

\section{Acknowledgements}

Part of the present work is supported by the Grant-in-Aid for Scientific Research of Japan Society for the Promotion of Science (No.24246095, No.15H04079) and 2013-MEXTSupported Program for the Strategic Research Foundation at Private Universities in Japan. This support is greatly appreciated.

\section{References}

[1] Takewaki, I., Murakami, S., Fujita, K., Yoshitomi, S. and Tsuji, M. The 2011 off the Pacific coast of Tohoku earthquake and response of high-rise buildings under long-period ground motions, Soil Dynamics and Earthquake Engineering, 2011; 31(11): 1511-1528.

[2] Takewaki, I., Fujita, K. and Yoshitomi, S. Uncertainties in long-period ground motion and its impact on building structural design: Case study of the 2011 Tohoku (Japan) earthquake, Engineering Structures, 2013; 49: 119-134.

[3] Housner, G.W., Behavior of structures during earthquakes. Journal of the Engineering Mechanics Division, ASCE, 1959; 85(4): 109-129.

[4] Trifunac, M.D., Hao, T.Y., and Todorovska, M.I, On energy flow in earthquake response, 
Report CE 01-03, July 2001, Univ. of Southern Calif., 2001.

[5] Trifunac, M.D., Energy of strong motion at earthquake source, Soil Dynamics and Earthquake Engineering, 2008; 28: 1-6.

[6] Takewaki, I., Bound of earthquake input energy to soil-structure interaction systems, Soil Dynamics and Earthquake Engineering, 2005; 25(7-10): 741-752.

[7] Berg, G.V., and Thomaides T.T. Energy consumption by structures in strong-motion earthquakes. Proceedings of 2nd World Conf. on Earthquake Engineering, Tokyo and Kyoto, 681-696, 1960.

[8] Housner, G.W. Measures of severity of earthquake ground shaking. Proc. of the US National Conf. on Earthquake Engineering, Ann Arbor, Michigan, 25-33, 1975.

[9] Housner, G.W., and Jennings, P.C. (1975) The capacity of extreme earthquake motions to damage structures. Structural and geotechnical mechanics: A volume honoring N.M.Newmark edited by W.J. Hall, 102-116, Prentice-Hall Englewood Cliff, NJ.

[10] Zahrah, T.F., and Hall, W.J. Earthquake energy absorption in SDOF structures. Journal of Structural Engineering, ASCE, 1984; 110(8): 1757-1772.

[11] Akiyama, H. (1985). Earthquake resistant limit-state design for buildings. University of Tokyo Press, Tokyo, Japan.

[12] Ohi, K., Takanashi, K., and Tanaka, H. A simple method to estimate the statistical parameters of energy input to structures during earthquakes. Journal of Structural and Construction Eng., Archi. Inst. of Japan, 1985; 347: 47-55 (in Japanese).

[13] Uang, C.M., and Bertero, V.V. Evaluation of seismic energy in structures. Earthquake Engineering and Structural Dynamics, 1990; 19: 77-90.

[14] Leger, P., and Dussault, S. Seismic-energy dissipation in MDOF structures. Journal of Structural Engineering, ASCE, 1992; 118(5): 1251-1269.

[15] Fajfar, P., and Vidic, T., Consistent inelastic design spectra: hysteretic and input energy. Earthquake Engineering and Structural Dynamics, 1994; 23(5): 523-537.

[16] Kuwamura, H., Kirino, Y., and Akiyama, H. Prediction of earthquake energy input from smoothed Fourier amplitude spectrum. Earthquake Engineering and Structural Dynamics, 1994; 23: 1125-1137. 
[17] Riddell, R., and Garcia, J.E. Hysteretic energy spectrum and damage control. Earthquake Engineering and Structural Dynamics, 2001; 30: 1791-1816.

[18] Takewaki, I. Frequency domain analysis of earthquake input energy to structure-pile systems, Engineering Structures, 2005: 27(4), 549-563.

[19] Kojima, K., Sakaguchi, K. and Takewaki, I. Mechanism and bounding of earthquake energy input to building structure on surface ground subjected to engineering bedrock motion, Soil Dynamics and Earthquake Engineering 2015; 70, 93-103.

[20] Lyon, R.H. Statistical energy analysis of dynamical systems, The MIT Press, Cambridge, MA, 1975.

[21] Ordaz, M., Huerta, B., and Reinoso, E. Exact computation of input-energy spectra from Fourier amplitude spectra, Earthquake Engineering and Structural Dynamics, 2003; 32: 597-605.

[22] Takewaki, I. Bound of Earthquake Input Energy, Journal of Structural Engineering, ASCE, 2004; 130(9): 1289-1297.

[23] Takewaki, I. Frequency domain modal analysis of earthquake input energy to highly damped passive control structures, Earthquake Engineering and Structural Dynamics, 2004; 33(5): 575-590.

[24] Takewaki, I., and Fujita, K. Earthquake input energy to tall and base-isolated buildings in time and frequency dual domains, J. of The Structural Design of Tall and Special Buildings, 2009; 18(6): 589-606.

[25] Boore, D.M. Stochastic simulation of high-frequency ground motions based on seismological models of the radiated spectra, Bulletin of the Seismological Society of America 1983, 73(6), 1865-1894.

[26] Schnabel, P.B., Lysmer, J. and Seed, H.B. SHAKE: A computer program for earthquake rsponse analysis of horizontally layered sites, A computer program distributed by NISEE/ Computer Applications, Berkeley, 1972.

[27] Kramer, S.L. Geotechnical earthquake engineering, Prentice Hall, 1996.

[28] Parmelee, R.A. The influence of foundation parameters on the seismic response of interaction systems, Proc. of the 3rd Japan Earthquake Engineering Symposium, Vol.3, 
49-56, 1970

[29] Alefeld G and Herzberger J. Introduction to interval computations. New York: Academic Press, 1983.

[30] Trifunac, M.D., Hao, T.Y. and Todorovska, M.I. On the reoccurrence of site specific response, Soil Dynamics and Earthquake Engineering, 1999; 18(8): 569-592. 
Table 1 Shallow and deep ground properties (nominal value)

\begin{tabular}{|c|c|c|c|c|}
\hline & $\begin{array}{c}\text { Shallow ground } \\
\text { (surface } \\
\text { ground) }\end{array}$ & $\begin{array}{c}\text { Upper layer of } \\
\text { engineering } \\
\text { bedrock }\end{array}$ & $\begin{array}{c}\text { Lower layer of } \\
\text { engineering } \\
\text { bedrock }\end{array}$ & $\begin{array}{c}\text { Earthquake } \\
\text { bedrock }\end{array}$ \\
\hline $\begin{array}{c}\text { Mass density } \\
\left(\times 10^{3} \mathrm{~kg}\right)\end{array}$ & 1.7 & 2.1 & 2.1 & 2.7 \\
\hline $\begin{array}{c}\text { Shear wave } \\
\text { velocity (m/s) }\end{array}$ & 200 & 400 & 1,000 & 3,200 \\
\hline Damping ratio & 0.05 & 0005 & 0.005 & Q value (300) \\
\hline
\end{tabular}

Table 2 Structural and foundation parameters

\begin{tabular}{|c|c|}
\hline & superstructure \\
\hline Fundamental natural period (fixed- base) & $0.525 \mathrm{~s}$ \\
\hline Fundamental natural circular frequency (fixed- base) & $11.97 \mathrm{rad} / \mathrm{s}$ \\
\hline Mass (equivalent mass for lowest mode) & $2.09 \times 10^{5} \mathrm{~kg}$ \\
\hline Mass height (equivalent height for lowest mode) & $12.8 \mathrm{~m}$ \\
\hline Foundation mass & $1.54 \times 10^{5} \mathrm{~kg}$ \\
\hline Damping ratio for superstructure & 0.02 \\
\hline Mass moment of inertia of superstructure & $1.12 \times 10^{6} \mathrm{kgm}^{2}$ \\
\hline Mass moment of inertia of foundation & $0.819 \times 10^{6} \mathrm{kgm}^{2}$ \\
\hline
\end{tabular}

Table 3 Model parameters for earthquake bedrock input

\begin{tabular}{|c|c|}
\hline Radiation pattern & 0.63 \\
\hline Amplification due to free surface & 2.0 \\
\hline $\begin{array}{c}\text { Reduction factor for partitioning of } \\
\text { energy into two horizontal components }\end{array}$ & 0.71 \\
\hline Cutoff frequency & $15 \mathrm{~Hz}$ \\
\hline Stress drop & $100 \mathrm{bar}$ \\
\hline Q value & 300 \\
\hline Distance from fault & $10 \mathrm{~km}$ \\
\hline Moment magnitude & 7.0 \\
\hline
\end{tabular}




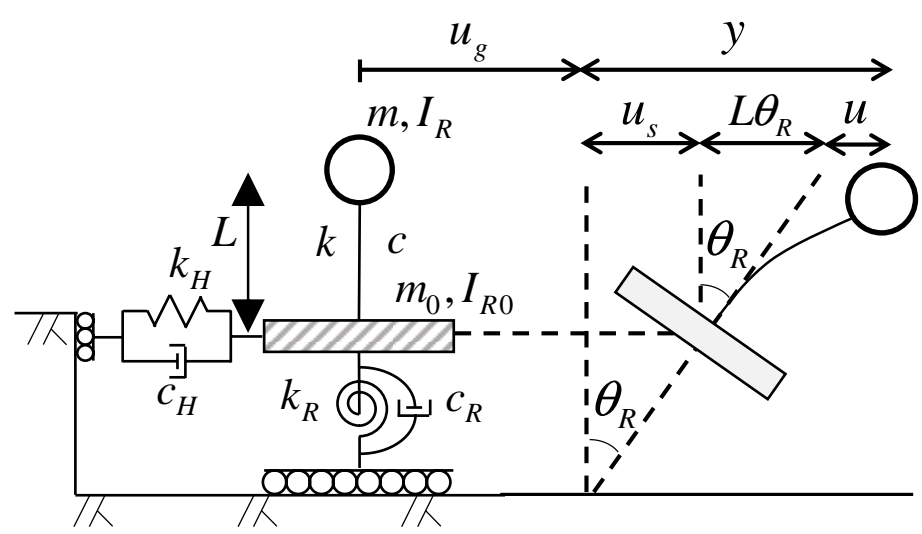

Fig.1 Swaying-rocking model subjected to free-field ground motion

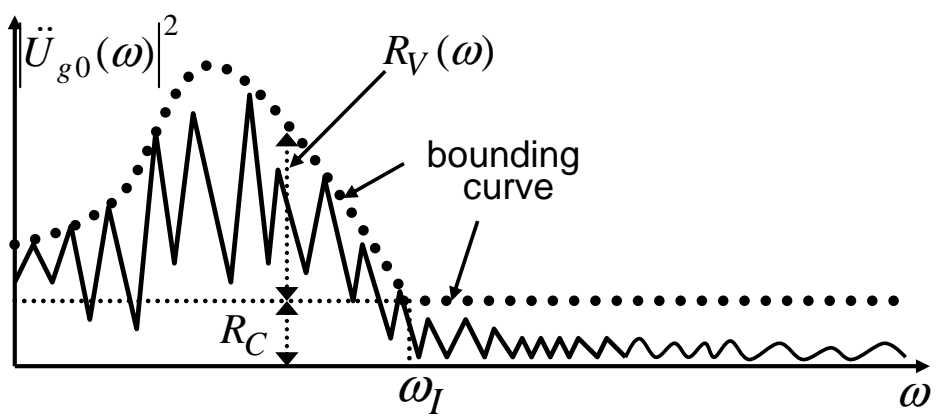

Fig.2 Squared Fourier spectrum of ground motion at engineering bedrock

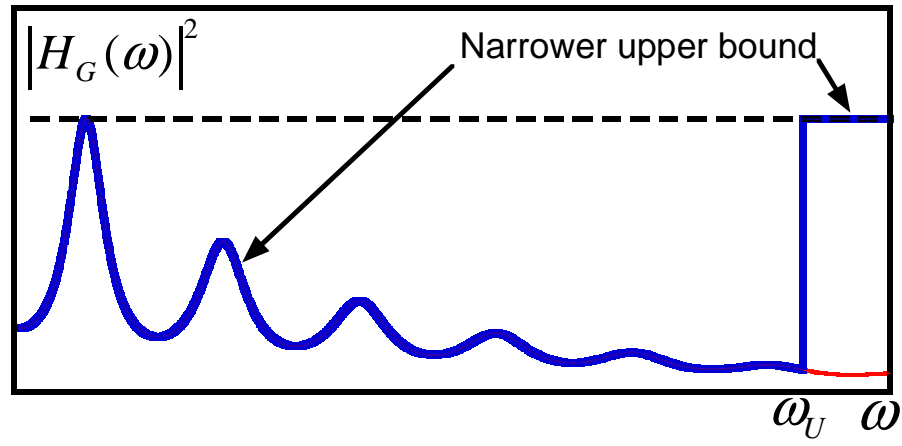

Fig.3 Narrower upper bound of surface ground amplification (damped case for surfaceground amplification) 


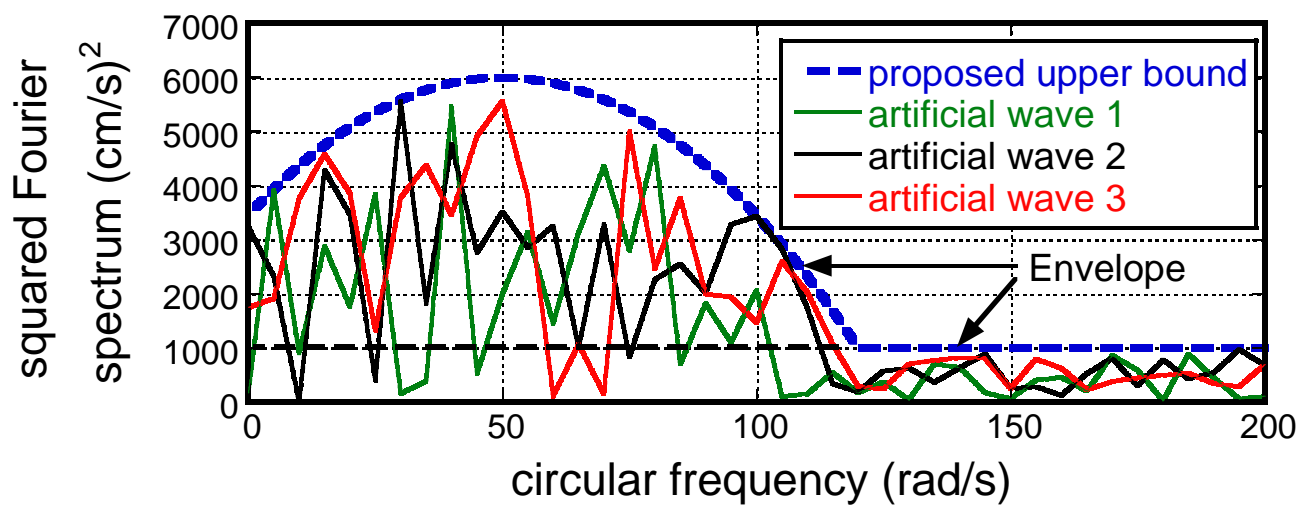

Fig.4 Squared Fourier spectra of three artificial ground motions at engineering bedrock surface and their upper bound model

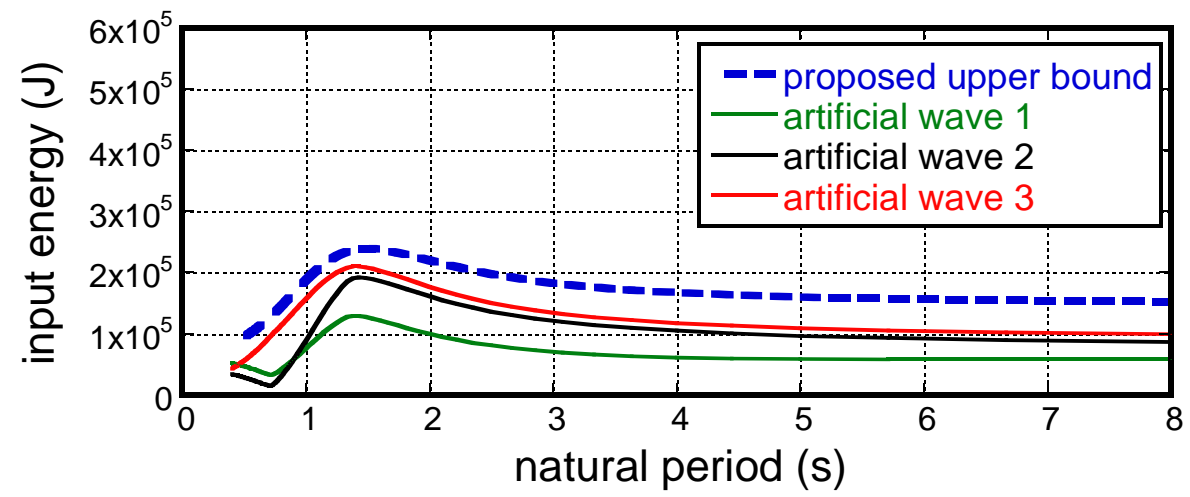

Fig.5 Proposed upper bound of earthquake input energy and realized earthquake input energy for three earthquake ground motions 


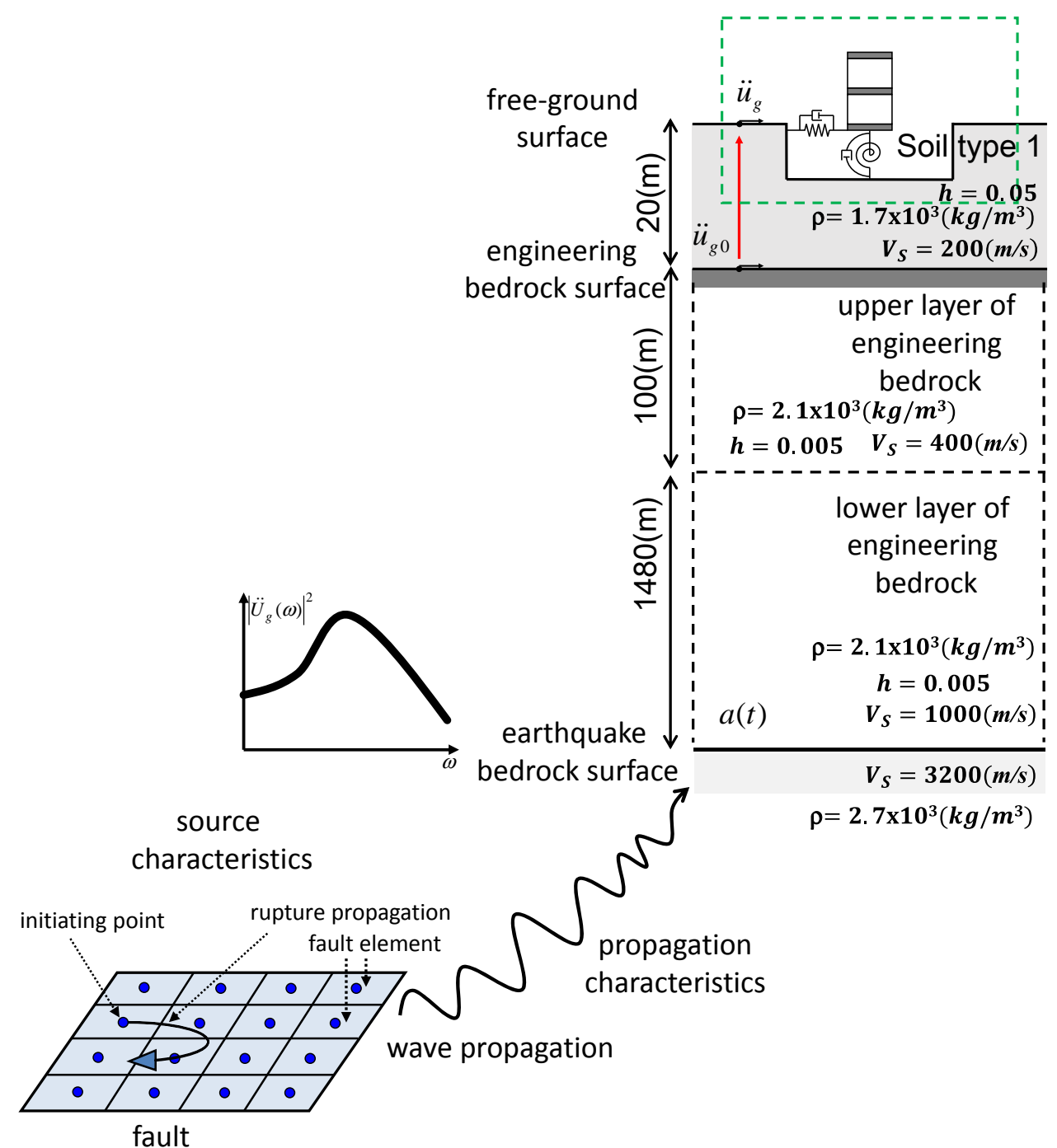

Fig.6 Earthquake energy input mechanism considering source characteristic, wave propagation characteristic and ground amplification characteristic

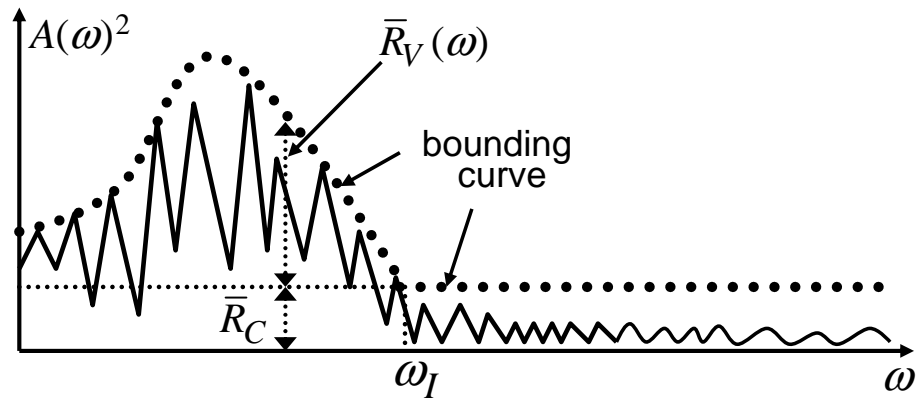

Fig.7 Squared Fourier spectrum of ground motion at earthquake bedrock 


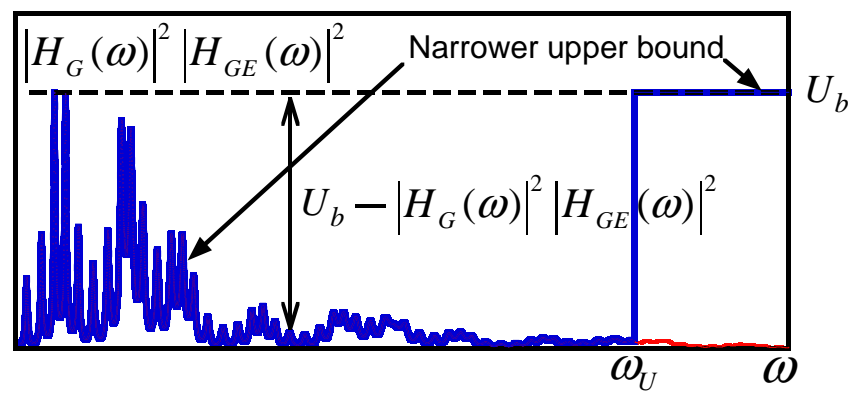

Fig.8 Narrower upper bound of squared transfer function of overall ground

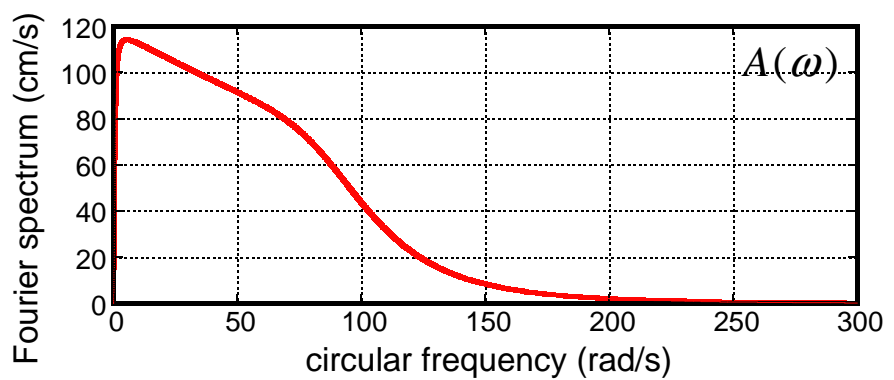

Fig.9 Fourier spectrum at earthquake bedrock surface

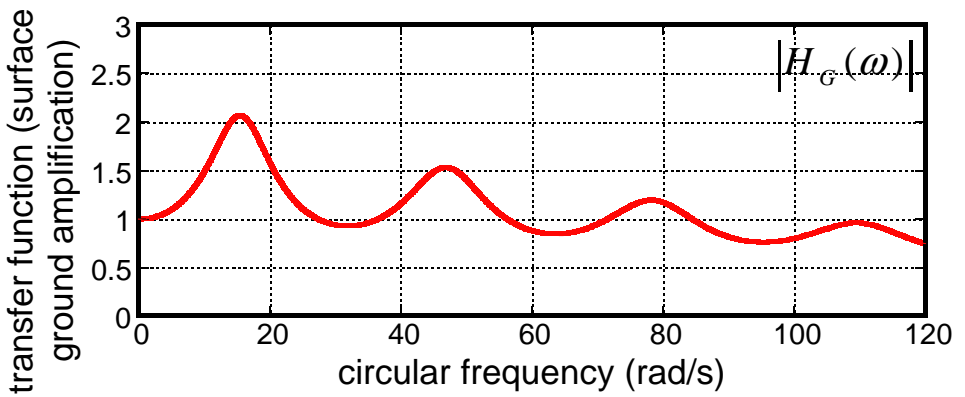

Fig.10 Transfer function of shallow ground of nominal model

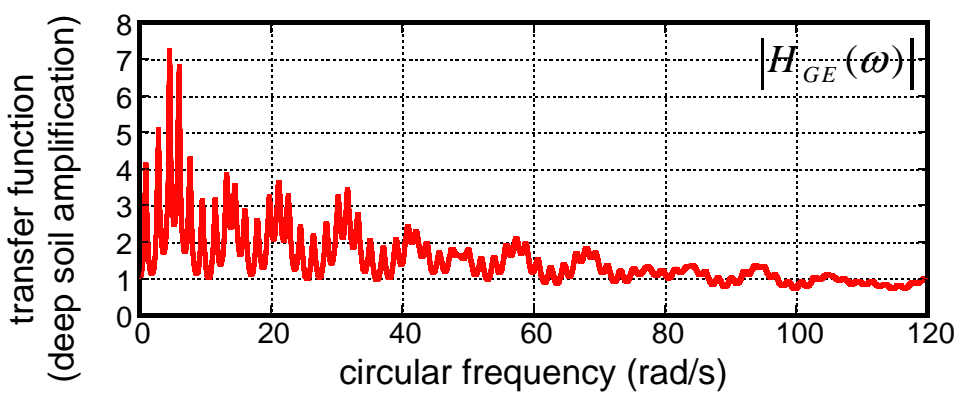

Fig.11 Transfer function of deep ground of nominal model 


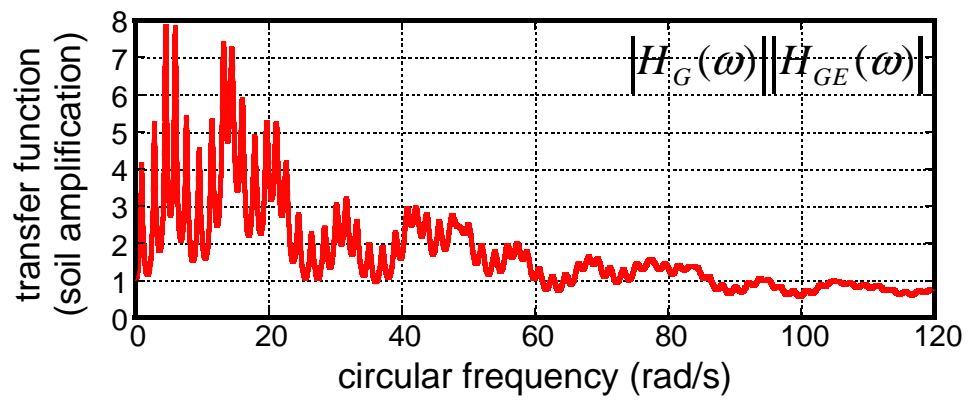

Fig.12 Transfer function of overall ground of nominal model

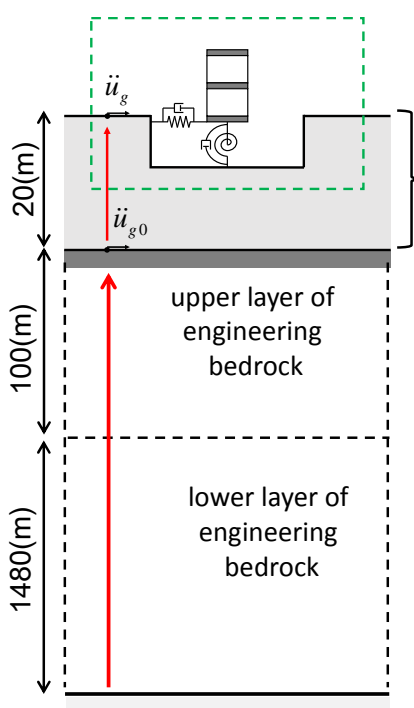

(a)

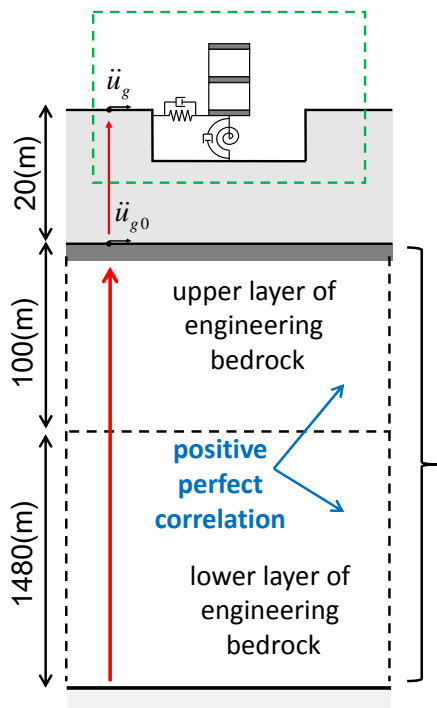

(b)

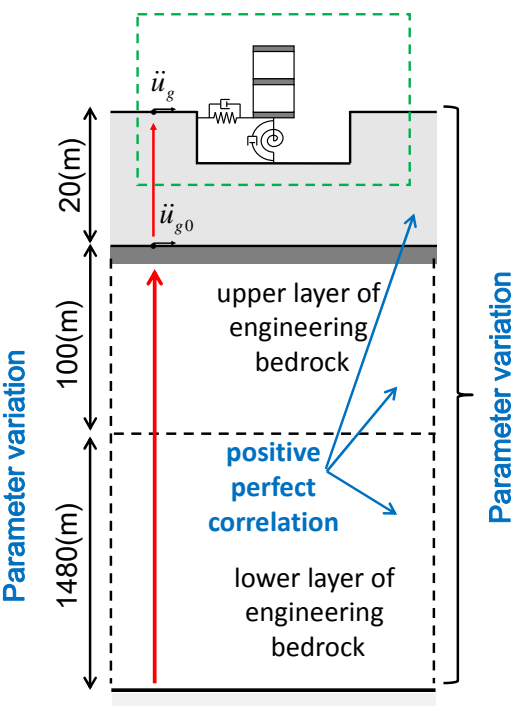

(c)

Fig.13 Variation cases in shallow, deep and overall ground

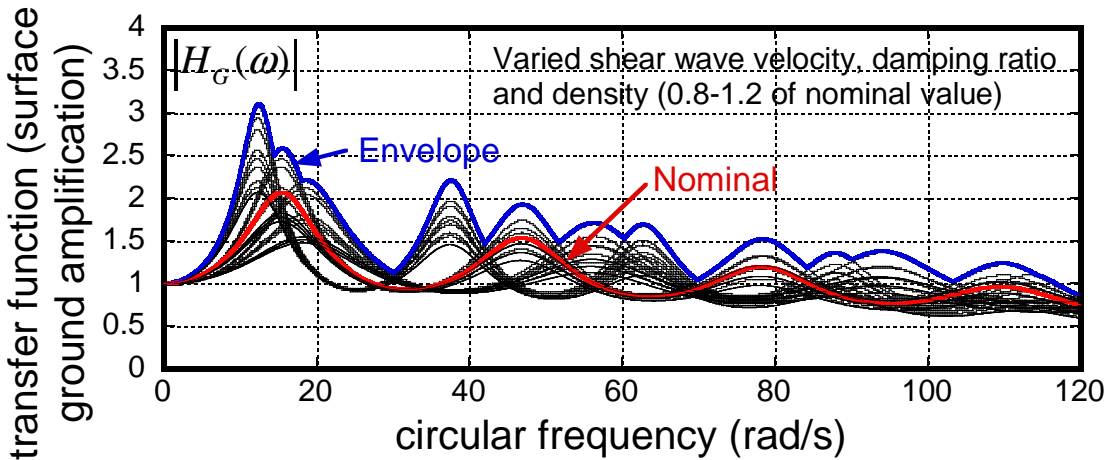

Fig.14 Envelope, nominal and realization (various combinations) of transfer function of shallow ground 


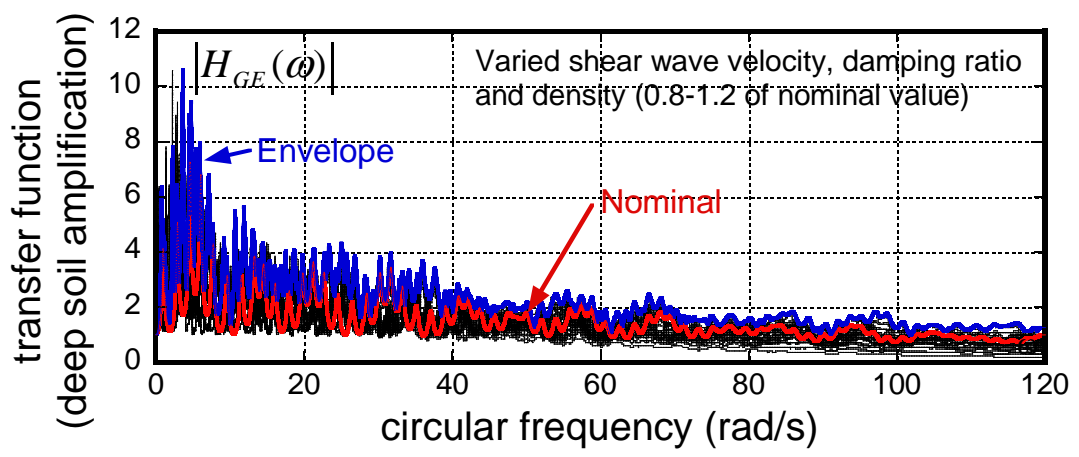

Fig.15 Envelope, nominal and realization (various combinations) of transfer function of deep ground

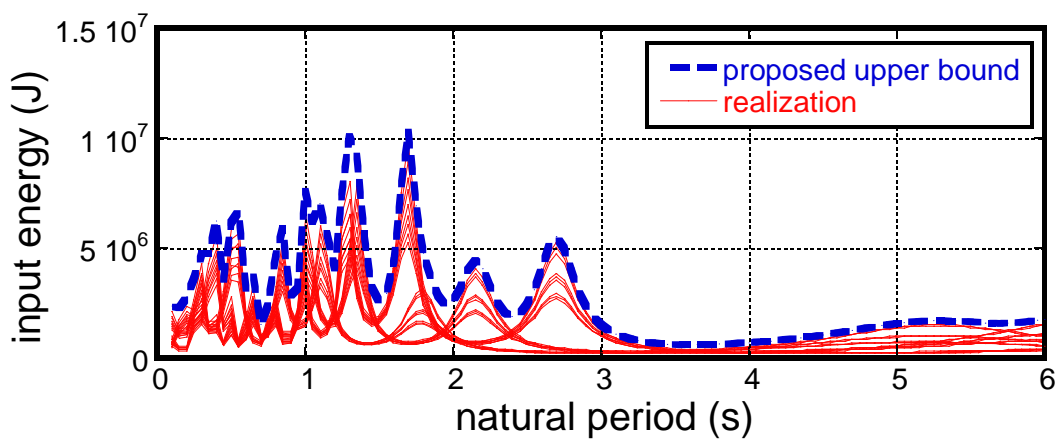

Fig.16 Proposed upper bound of earthquake input energy to SR model on uncertain shallow and deep ground subjected to certain input at earthquake bedrock 